\title{
Endividamento público, crescimento, moeda e inflação: comentário a “Matemática agradável”, de Gerson Lima
}

\author{
FABRÍCIO PITOMBO LEITE \\ GUSTAVO DE OLIVEIRA AGGIO \\ EDUARDO ANGELI
}

The paper aims at analyzing the article by Gerson Lima on the manner by which fiscal deficit should be covered. It presents a more general dynamic model, where the principle of effective demand is explicitly used. By doing that, it is possible to treat as endogenous variables the national income and the government entries, what brings the result that the public debt must not follow an explosive path unless the very restrictive conditions of Lima's paper prevail. It also evaluates Lima's implicit inflation theory, and argues against his approximation to Friedman's framework.

Keywords: public debt; monetary policy; money issuing.

JEL Classification: E5; E6.

\section{INTRODUÇÃO}

O presente texto é um comentário ao trabalho publicado por Gerson Lima, "Matemática Agradável”, no qual o autor argumenta que, em geral, o financiamento dos gastos fiscais a partir da emissão de títulos públicos segue uma trajetória em que a dívida se torna explosiva. Como uma alternativa superior, Lima (2008) propõe a monetização do déficit público, que em seu modelo, além de não gerar uma espiral inflacionária, pode induzir um aumento tanto do PIB quanto da arrecadação tributária.

Nosso objetivo é apontar alguns limites da proposta de Lima (2008), buscando, ao tornar seu modelo mais geral, testar a consistência de suas conclusões. Para

\footnotetext{
* Respectivamente, doutorando em Economia na Unicamp, bolsista Capes. E-mail: fabriciopleite@eco. unicamp.br; doutorando em Economia na Unicamp, bolsista Capes. E-mail: gustavoaggio@hotmail. com; doutorando em Economia na Unicamp, bolsista CNPq. E-mail: angeli@eco.unicamp.br.
} 
tanto, na segunda seção tornamos endógenas a renda nacional e a receita tributária, de modo a mostrar que o endividamento público não segue necessariamente uma trajetória explosiva. Na terceira seção, julgamos a aproximação tentada por Lima (2008) com a visão monetarista do processo inflacionário como oriunda da ausência de uma teoria da inflação mais completa por parte do autor; ademais, realizamos alguns exercícios que sugerem que o resultado alcançado por Lima (2008) se torna um caso particular quando é admitido um estoque preexistente de dívida pública.

\section{UM MODELO MAIS GERAL PARA A TRAJETÓRIA DA ECONOMIA}

O objetivo desta seção é desenvolver alguns pontos deixados em aberto pelo professor Gerson Lima (2008), o que nos leva a qualificar algumas de suas conclusões fundamentais a partir de modificações no arcabouço utilizado por esse autor para descrever a trajetória da dívida pública. Para tanto, partiremos da identidade contábil apresentada pelo mesmo (p. 473), a qual explicita que a soma dos gastos fiscais $(G F)$ e com pagamento de juros $(G J)$, realizados pelo governo, deve ser igual à receita tributária $(T)$ acrescida das emissões de títulos da dívida pública $\left(D-D_{-1}\right)$ e de base monetária $\left(M-M_{-1}\right)$.

Radicalizando um pouco o argumento, consideraremos aqui que o governo se financia, além de pela receita tributária, somente a partir de emissões de títulos da dívida, prescindindo da prerrogativa de emitir moeda. Desse modo, nossa primeira equação corresponde a

$$
G F+r D_{-1}=T+\left(D-D_{-1}\right)
$$

com os gastos fiscais expressos por $G F$ e os gastos com juros representados por $r$ (taxa nominal de juros) multiplicando $D_{-1}$ (montante da dívida pública no período anterior). Como em Lima (2008), a receita tributária é representada por $T$ e a dívida pública no período corrente por $D$. Claro está, rearrumando alguns termos, que essa equação pode ser vista como uma equação em diferenças em que a dívida no período corrente é função da dívida no período anterior, bem como de outras variáveis exógenas:

$$
D=(1+r) D_{-1}+G F-T
$$

Desse modo, não pode causar surpresa a conclusão do professor Gerson Lima de que a trajetória da dívida é explosiva, a menos que a taxa de juros seja negativa, uma vez que a condição de convergência para um equilíbrio estável requer que o coeficiente relacionado à variável no período anterior seja menor que a unidade, em módulo. Tudo isso se efetivamente tomarmos as outras variáveis da equação como exógenas, uma vez que assim as mesmas só determinariam a solução de estado estacionário, não tendo qualquer influência no processo de convergência da série. A exemplo do efetuado pelo autor, tomaremos o gasto fiscal como "variável autônoma, no sentido de que o governo fixa seu valor de modo independente do nível de atividade da economia" (p. 473), nos restringindo a tecer considerações 
acerca do nível de atividade e de suas repercussões na receita tributária, tornando endógenas essas variáveis. Tal extensão também é sugerida pelo autor (p. 480).

Aqui começam nossas qualificações à abordagem do professor Gerson Lima, uma vez que considerações acerca da evolução da renda ao longo do tempo não estão claras o bastante em seu trabalho. ${ }^{1}$ Julgamos necessário promover tais considerações, pois, a partir das mesmas, alterações na receita tributária ocorrem e, com elas, alterações também nas necessidades de emissão de dívida para cobrir um eventual déficit. Assim sendo, partiremos do princípio de que o gasto gera a renda, conhecido como princípio da demanda efetiva e traduzido no mecanismo do multiplicador, no qual um gasto autônomo à renda é capaz de dar partida a um processo de realimentação dos gastos privados induzidos por esta, acarretando sua elevação.

Necessitaremos explicitar, para tal, ao lado da equação (1), algumas equações simples que dizem respeito à renda agregada, à receita tributária e a uma função dos gastos privados, podendo esta última ser entendida, numa primeira aproximação, como uma função consumo típica, a qual é necessária para fazer funcionar o mecanismo do multiplicador.

Quanto à receita tributária, faremos essa uma função da renda e dos ganhos com juros da dívida no período anterior:

$$
T=\theta\left(Y+r D_{-1}\right)
$$

Fazendo os gastos privados (GP) dependerem da renda disponível (excetuando impostos) e da riqueza acumulada no período anterior, podemos escrever:

$$
G P=\alpha_{1}\left(Y+r D_{-1}-T\right)+\alpha_{2} D_{-1}
$$

Finalmente, para fechar o sistema, uma condição usual acerca de uma identidade contábil é requerida: ${ }^{2}$

$$
Y=G P+G F
$$

\footnotetext{
${ }^{1}$ No sentido de que não parece haver qualquer mecanismo que descreva o comportamento dinâmico da renda, mas somente considerações acerca da possibilidade desta não permanecer constante entre dois períodos, o que implica, quando muito, um procedimento exógeno de mudança na renda. Ademais, a única anuência a uma relação entre gastos fiscais e receita tributária (via crescimento do PIB) se dá em sua discussão acerca da monetização do déficit, o que rende resultados, não por coincidência, condizentes com a perspectiva monetarista, uma vez que a ligação positiva postulada é entre o estoque de moeda e a receita tributária. Desse modo, a reivindicação de Lima $(2008$, p. 487) de que seria o gasto fiscal, e não o aumento do estoque de moeda, o causador do "aumento de produção e preços" não procede, uma vez que sua hipótese acerca da elevação da renda é restrita ao caso do financiamento por monetização, não incorporando adequadamente a ideia de que é o gasto, não importando a forma de financiamento, que gera um aumento na renda.

${ }^{2}$ Aqui, por motivos de simplificação, estão ausentes quaisquer considerações sobre o investimento e seus efeitos sobre o estoque de capital fixo, até porque não há escolha alguma de portfolio envolvida no modelo; ou seja, por hipótese (necessária à radicalização do argumento vislumbrada), o único modo de transportar riqueza ao longo do tempo é através de títulos da dívida pública. Visto de um outro ângulo, o governo sempre consegue se financiar junto ao público através da emissão de dívida, a uma taxa de juros fixa. O modelo ora desenvolvido tem por base a família de modelos conhecida como de consistência fluxo-estoque (stock-flow consistent - SFC), tal como apresentada por Godley \& Lavoie (2007).
} 
A partir dessas quatro equações ( 1 a 4 ) podemos chegar num sistema de três equações em diferenças, onde as variáveis dependentes, $Y, T$ e $D$, estão relacionadas a somente uma variável defasada, $D_{-1}$ :

$$
\begin{aligned}
& Y=\frac{G F+\left[\alpha_{2}+\alpha_{1} r(1-\theta)\right] D_{-1}}{1-\alpha_{1}(1-\theta)} \\
& T=\frac{\theta\left[G F+\left(\alpha_{2}+r\right) D_{-1}\right]}{1-\alpha_{1}(1-\theta)} \\
& D=G F+\frac{\left[\left(1-\alpha_{1}+r-\alpha_{1} r\right)(1-\theta)+\theta\left(1-\alpha_{2}\right)\right] D_{-1}-\theta G F}{1-\alpha_{1}(1-\theta)}
\end{aligned}
$$

Assim, podemos perceber que a relação entre os títulos de dívida no período corrente e os mesmos no período anterior depende de uma série de parâmetros, dentre os quais a taxa de juros. Uma inspeção preliminar da equação (7) já poderia nos levar a concluir que esta não segue, inexoravelmente, uma trajetória explosiva. Como já ressaltado, todas as três equações do sistema $(5,6$ e 7$)$ dependem de somente uma variável defasada, $D_{-1}$, além de outros fatores exógenos (relacionados à solução particular). Isso equivale a dizer que a matriz que nos dá a solução homogênea do sistema é constituída de duas colunas de zeros e, portanto, apresenta dois autovalores iguais a zero, restando a apenas um autovalor o papel de determinar a estabilidade do sistema. Pode-se demonstrar que, nesse caso, o autovalor restante é igual à parte ligada à solução homogênea da equação (7), traduzida na função $\Phi$, abaixo:

$$
\Phi=\frac{\left(1-\alpha_{1}+r-\alpha_{1} r\right)(1-\theta)+\theta\left(1-\alpha_{2}\right)}{1-\alpha_{1}(1-\theta)}
$$

Para simplificar a exposição, apresentaremos, a partir desse ponto, alguns resultados de um exercício de simulação feito a partir de determinados valores para os parâmetros. ${ }^{3}$ Considerando uma taxa de juros $(r)$ de $10 \%$, uma alíquota de impostos $(\theta)$ de $35 \%$, e valores de $\alpha_{1}$ e $\alpha_{2}$ respectivamente iguais a 0,7 e 0,3 , obtivemos $\Phi=0,843$, sendo, portanto, a dívida (e todo o sistema) monotonicamente convergente. Com um valor constante para os gastos fiscais do governo $(G F)$ equivalente a 30, sendo que esse altera somente a solução de equilíbrio estacionário e, desse modo, a escala das soluções, por assim dizer, obtivemos valores de equilíbrio de 98,42 para a renda $(Y), 36,42$ para a receita tributária $(T)$ e 68,42 para o estoque de títulos de dívida $(D)$. Vale notar que a diferença entre $G F$ e $T$ corresponde aos pagamentos de juros por parte do governo, sendo o déficit, por definição,

\footnotetext{
${ }^{3}$ As simulações foram realizadas utilizando o software Mathematica 5.1. Cabe destacarmos que as soluções analíticas do sistema, apesar de perfeitamente obteníveis, são intricadas o bastante para trabalharmos somente com os resultados de simulação.
} 
zerado no estado estacionário. Todas as variáveis determinadas a partir do sistema tiveram seus valores iniciais estabelecidos em zero.

A evolução dessas variáveis pode ser mais adequadamente descrita a partir de um gráfico, como o apresentado abaixo, onde se nota o processo de convergência a um equilíbrio estável.

Gráfico 1: Evolução das variáveis obtida por meio de simulação

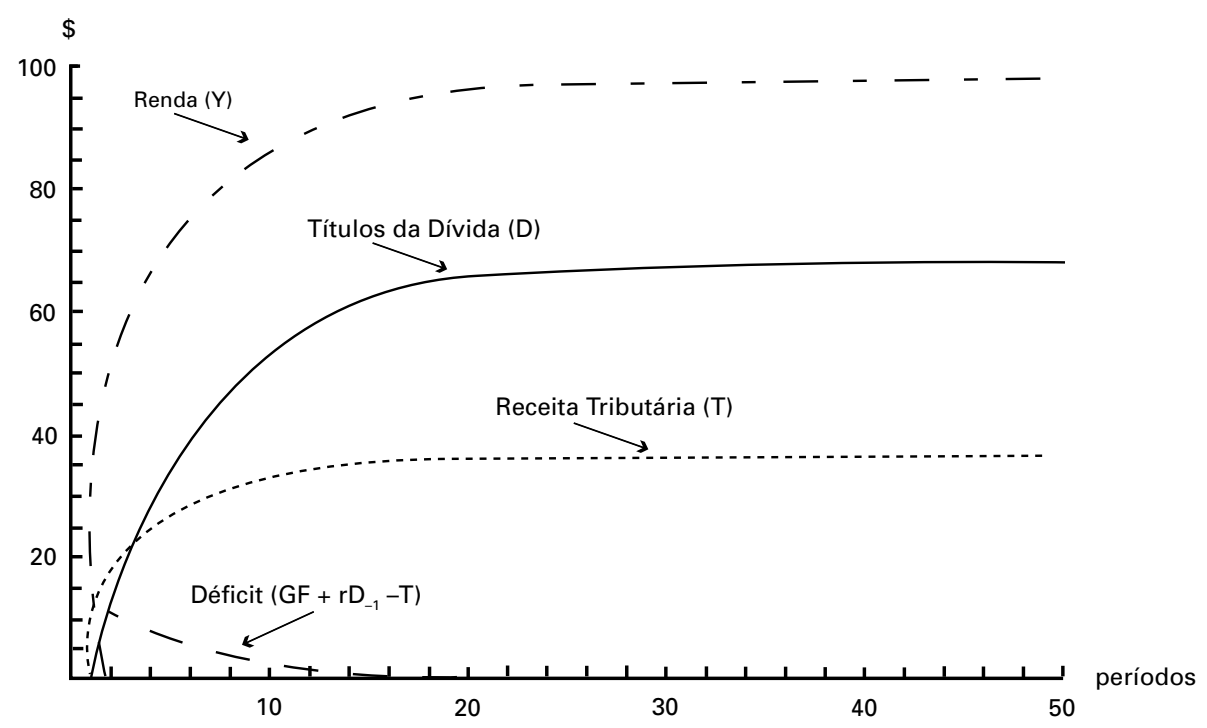

A essa altura, necessitamos destacar que o caso em que as variáveis seguem uma trajetória convergente tampouco é o único possível a partir de nosso sistema de equações em diferenças. Considerando os mesmos valores estabelecidos acima para os parâmetros, à exceção de $\alpha_{2}$, poderíamos encontrar um valor para este em que a trajetória deixe de ser convergente. ${ }^{4}$ Assim, dados $r=0,1, \theta=0,35$ e $\alpha_{1}=0,7$, o valor de $\alpha_{2}$ que faz com que a trajetória não convirja é qualquer um menor ou igual a 0,0557 , aproximadamente. Considerando como plausíveis os valores para os outros parâmetros, tal condição não nos parece muito restritiva.

Como podemos notar, quão maiores os níveis de gastos a partir da riqueza acumulada, mais rápida será a convergência ao estado estacionário. Formalmente,

$$
\frac{\partial \Phi}{\partial \alpha_{2}}=\frac{-\theta}{1-\alpha_{1}(1-\theta)}<0
$$

para qualquer valor aceitável dos parâmetros envolvidos $\left(0<\alpha_{1}, \alpha_{2}, \theta<1\right.$ e $\left.r>0\right)$.

\footnotetext{
${ }^{4}$ Esse exercício poderia ser feito, logicamente, para qualquer um dos parâmetros, a fim de encontrarmos valores "críticos" de um parâmetro em função de todos os outros. Tomamos o caso de $\alpha_{2}$ por ser este, possivelmente, objeto de maior suspeição.
} 
Também para a taxa de juros, podemos estabelecer uma relação similar, envolvendo somente os mesmos parâmetros, o que qualifica as conclusões do professor Gerson Lima de que a dívida seguiria uma trajetória explosiva para qualquer valor positivo de $r$, sem contradizer, no entanto, a intuição subjacente de que a dívida converge mais rapidamente com valores mais baixos para a taxa de juros:

$$
\frac{\partial \Phi}{\partial r}=\frac{(1-\theta)\left(1-\alpha_{1}\right)}{1-\alpha_{1}(1-\theta)}>0
$$

Mais ainda, se levássemos adiante o exercício de encontrar "valores críticos" para os parâmetros da função $\Phi$, chegaríamos à conclusão de que, dados os valores dos outros parâmetros, $\alpha_{1}=0,7, \alpha_{2}=0,3$ e $\theta=0,35$, a taxa de juros $(r)$ teria de ser maior ou igual a $53,85 \%$ para fazer com que o sistema não convergisse para uma situação de equilíbrio estacionário.

\section{INVESTIGAÇÃO ACERCA DA TEORIA DA INFLAÇÃO SUBJACENTE NA “MATEMÁTICA AGRADÁVEL”}

Voltemos agora para a questão da análise da proposta do texto a partir da investigação da teoria de inflação que está subjacente ao argumento do professor Gerson Lima. O autor assume que o crescimento do PIB, que ocorre em consequência de uma expansão fiscal deficitária, não gera "inflação elevada ou descontrolada", uma vez que o estoque de moeda se estabiliza com o novo patamar de gastos (Lima, 2008, p. 472).

Percebe-se que a proposta de Lima (2008) está alinhada à retomada pós-keynesiana da Teoria das Finanças Funcionais (TFF). Analiticamente, a TFF, em seu retorno, permite um entendimento institucional sobre o processo de criação e destruição de moeda (Bell, 2000; Bell \& Wray, 2003; Wray, 1998) que incorpora definitivamente a noção de criação endógena de moeda. Afasta-se, com isso, de hipóteses demasiadamente irrealistas como a de Milton Friedman, segundo a qual a adição de moeda na economia poderia ser considerada como se tivesse sido jogada por helicópteros (Friedman, 1969, p. 4), ou a de Don Patinkin (1965, p. 4), segundo a qual a moeda cairia do céu como o maná do povo judeu em êxodo. Evidentemente, uma teoria que supõe que "fatores condicionantes da base monetária estão associados a operações do lado real da economia" (Lima, 2008, p. 484) está mais bem qualificada para interpretar variações no lado real da economia causadas pelo fenômeno da moeda do que uma teoria que supõe a criação exclusivamente exógena da moeda.

Por outro lado, a TFF demonstra, desde seu artigo seminal (Lerner, 1943), baixa preocupação teórica com o fenômeno da inflação. Lerner simplesmente postula que pouca moeda causa recessão e muita moeda, emissão de moeda que induza a produção a um nível acima do pleno emprego de fatores, causa inflação, proposta alinhada à definição de inflação real de Keynes ([1936] 1973, pp. 118-119; 
303-304). Wray (1998, p. 123) é explícito ao declarar que não possui preocupação quanto a um processo de variação crescente de um específico índice de preços, mas somente com a manutenção do valor relativo dos salários. Este autor define que o valor real da moeda corresponderia ao esforço necessário para conseguir tal quantidade de capacidade de aquisição de mercadorias (Wray, 2002, p. 91; 2003, p. 105), ligando sua proposta de obtenção do pleno emprego, via o papel de empregador de última instância do Estado, a uma âncora de poder de compra dos salários, que consequentemente deveria se tornar indexada em um processo inflacionário.

Talvez a proposta de Randall Wray seja a mais extrema desse conjunto teórico e não podemos inferir, a partir da leitura do artigo do professor Gerson Lima, que seja esta a teoria de inflação subjacente nesse trabalho. Porém, quando o autor defende a elaboração de um orçamento prevendo o financiamento de investimento a taxa de juros zero e chega à conclusão de que o processo apenas levará a um aumento no nível de preços, porque o estoque de moeda atinge um nível de equilíbrio, e não a um processo inflacionário, está subjacente que o professor Gerson Lima aceita a hipótese de que a possibilidade de um processo inflacionário ser desencadeado só existe após o ponto de pleno emprego ter sido alcançado. ${ }^{5}$ Mesmo que aceitássemos a tese de que a emissão de moeda após o pleno emprego não causa, necessariamente, inflação, como o faz o professor Gerson Lima (p. 486), não poderíamos decorrer disso que antes do pleno emprego o processo de elevação recorrente dos preços não aconteça. A história econômica brasileira da crise da dívida no início dos anos 1980 até o estabelecimento do Real configura clara evidência deste fato.

A conclusão do professor Gerson Lima é que o crescimento moderado da base monetária poderia financiar completamente os gastos do governo sem gerar um processo inflacionário. Consciente ou não da limitação teórica da TFF quanto à inflação, o professor Gerson Lima busca refúgio teórico na proposta de regra de crescimento dos agregados monetários de Milton Friedman (Lima, 2008, p. 486). Julgamos pouco apropriada esta aproximação do autor com a ótica monetarista. Explicitemos o porquê.

O primeiro ponto é que o crescimento da economia, da variável PIB, ocorre, na teoria de Friedman, ao menos no longo prazo, exclusivamente por fatores reais tais como a acumulação de capital, crescimento da população e progresso tecnológico. A moeda é sempre neutra no longo prazo, sendo que no curto prazo variações da oferta de moeda causam erros de interpretação dos agentes econômicos que são corrigidos através de um processo de expectativas adaptativas (Friedman, 1968, pp. 7-10; 1977, pp. 456-459). Disto Friedman (1970) chega à conclusão de que se o aumento da base monetária variasse proporcionalmente ao aumento do produto,

\footnotetext{
${ }^{5} \mathrm{O}$ professor Gerson Lima não é explícito nesse ponto, mas podemos chegar a esta conclusão porque no pleno emprego, por definição, a economia não pode crescer mais; se a cada adição de moeda há uma elevação de nível de preços e a adição de moeda se torna sistemática, configura-se um processo inflacionário.
} 
satisfaria a variação da demanda de moeda para transações, sem alterar o nível de preços e a taxa nominal de juros, refletindo no curto prazo o resultado que no longo prazo os preços relativos e a taxa real de juros se mantêm inalterados.

A regra de crescimento fixo da base monetária deveria ser utilizada de forma pragmática, porque não se sabe ao certo qual a taxa de crescimento natural da economia. Os agentes, de posse da informação acerca do crescimento percentual anual da base monetária, antecipam a elevação dos preços e não alteram o produto de equilíbrio, não necessitando que a taxa de juros nominal se eleve para trazer a taxa real ao seu suposto nível natural (Friedman, 1968, pp. 14-17).

A concepção mecanicista de Friedman é possível dada a sua teoria de criação exógena de moeda, que explicitamente considera a distinção entre moeda e crédito bancário (Friedman 1970, p. 155). ${ }^{6}$ Se houvesse uma regra, como sugere o professor Gerson Lima, de financiamento anunciado de investimento público com emissão de moeda, a expectativa adaptativa presente na ótica monetarista se transmutaria, dada a recorrência do fato pela normatização, em expectativas racionais dos agentes. Quando isso ocorresse, teoricamente, os preços e a taxa de juros nominal se elevariam imediatamente e parte do gasto público simplesmente substituiria parte do gasto privado.

Concluímos com isso que a TFF necessita urgentemente de uma teoria própria e não monetarista, porque são teorias antagônicas, sobre a inflação, que, de preferência, explique também a inflação antes do ponto de pleno emprego.

Além da ausência de uma teoria da inflação antes do ponto de pleno emprego, a análise do professor Gerson Lima se mostra incompleta quando estuda a variação da base monetária. Isso ocorre porque em seu modelo é suposto que não existe dívida passada.

Quando o professor Gerson Lima afirma que um estoque finito de moeda criado para financiar uma expansão fiscal pode acarretar apenas uma elevação do patamar de preços, que não culmina em um processo inflacionário (Lima, 2008, pp. 483-484), ficamos satisfeitos com a demonstração de forma elegante de um caso particular. O que preocupa é a conclusão do autor que parece indicar este caso como geralmente possível e recomendável para as autoridades fiscais e monetárias. Passemos, então, a discorrer sobre uma série de outros casos especiais que falseiam a generalidade do modelo do professor Gerson Lima suposta em sua conclusão. No primeiro exemplo utilizaremos a metodologia do professor e nos seguintes abriremos mão dessa opção.

Quando não há um estoque de dívida, a quantidade de moeda necessária a ser emitida é fornecida pela equação: ${ }^{7}$

$$
M=M_{-1}-(T-G F)
$$

\footnotetext{
${ }^{6}$ Cumpre lembrar que, na TFF, parte da moeda é criada pelos bancos.

${ }^{7}$ Esta equação foi também proposta por Lima (2008, p. 484), com a adição de um termo relativo ao superávit em transações correntes, posteriormente eliminado pelo autor. Como tratamos sempre de uma economia fechada ao longo do presente comentário, preferimos desconsiderá-lo de imediato.
} 
Esta criação de moeda resultaria em um estoque estável de moeda quando causasse um aumento da produção e, consequentemente, um aumento da arrecadação, de forma a obedecer à seguinte condição: ${ }^{8}$

$$
T=\gamma_{0}+\gamma_{1} M+\gamma_{2} O V
$$

onde $O V$ representa outras variáveis. De acordo com Lima (2008, p. 487), podemos esperar um aumento do produto e da arrecadação porque "o que causa um aumento de produção e preços é um gasto fiscal maior e não apenas um saldo mais elevado de moeda". Ou seja, é neste caso específico, seguindo a tradição da TFF, que $\gamma_{1}$ é estritamente positivo, o que garante a condição de estabilidade:

$$
0<\left[1 /\left(1+\gamma_{1}\right)\right]<1
$$

Suponhamos agora, o que ocorre no caso mais realista, que o país possui um estoque $\bar{D}$ de dívida passada. ${ }^{9}$ Se a amortização se dá por $\delta \bar{D}$, onde $\delta$ é uma fração qualquer da dívida a ser paga no período corrente, e se esse pagamento for realizado com emissão de moeda, a equação de criação de moeda deverá ser:

$$
M=M_{-1}-(T-G F)+\delta \bar{D}
$$

Por simplicidade, suponhamos que $(T-G F)=0$, o que implica $\gamma_{1}$ se tornar um parâmetro relacionado com a criação de demanda derivada do pagamento da dívida. Não abrimos mão, como é evidente na seção anterior, da hipótese de que esta transferência pode gerar renda, mas estamos atentos ao fato de que passamos à esfera da decisão do agente privado da economia que recebeu este fluxo, diferentemente do caso em que o gasto fiscal, gasto em bens e serviços adquiridos na economia real pelo governo, é financiado com emissão de moeda. No caso particular onde a propensão marginal a consumir do rentista tende a zero, $\gamma_{1} \rightarrow 0 \mathrm{e} 1 /\left(1+\gamma_{1}\right) \rightarrow 1$, tornando a observância matemática de um equilíbrio do estoque de moeda indeterminado.

Abramos mão agora da simplicidade e da elegância da opção metodológica acerca do uso de relações lineares bem determinadas e passemos à análise complexa das relações econômicas que é bem comum no pensamento de Keynes e dos pós-keynesianos. ${ }^{10}$

Imaginemos o caso, novamente insistimos, mais realista onde existe um estoque de dívida que representa uma quantia considerável do produto nacional. Não é realista pensar que mesmo sendo válidas as relações obtidas pelo professor Gerson Lima entre a criação de moeda e o aumento do produto que gere um equilíbrio sem processo inflacionário, que o pagamento da dívida de uma vez por todas seja acei-

\footnotetext{
${ }^{8}$ Condição também encontrada em Lima (2008, p. 484). Substituímos os parâmetros alfas do original por gamas para evitar confusão com os parâmetros utilizados na seção anterior.

${ }^{9}$ Aqui consideramos o estoque de dívida como fixado para tornar a exposição mais simples e trazermos o foco para o caso da monetização.

${ }^{10}$ Também fora desta tradição econômica, como bem sumarizado em Foley (2003).
} 
tável. Isso porque o aumento no patamar de preços, e não processo inflacionário como defende o autor, seria tamanho que poderia comprometer a renda de todos os agentes que possuem contratos monetários fixos, como, por exemplo, os trabalhadores assalariados. Sendo assim, abrimos mão de analisar mais este caso particular que se mostra obviamente fora de questão. Tomemos por definição que em cada período de tempo o governo paga apenas a amortização e os juros do estoque de dívida observado. Analisemos duas possibilidades.

$\mathrm{Na}$ primeira possibilidade, imaginemos que os acréscimos de moeda na economia conduzem, período a período, a aumentos no PIB e na arrecadação que destroem parte de nova moeda emitida e proporcionam uma elevação de patamar de nível de preços sem que haja um processo inflacionário. Neste cenário podemos pensar em dois desdobramentos: (i) a dívida é inteiramente paga e o modelo particular do professor Gerson Lima passa a ser sempre válido; (ii) a economia atinge o pleno emprego, dados seus recorrentes crescimentos, mas o estoque da dívida ainda é positivo. Neste caso, necessariamente o modelo do professor deixa de ter validade porque, como já insistimos, após o pleno emprego a economia não pode crescer mais e se não houver uma forma de destruição da moeda, tributação excedente ou emissão de títulos, o processo inflacionário será inevitável. Obviamente a tributação não atinge necessariamente os detentores das novas variações de moeda, configurando que a emissão de nova dívida se torna necessária e, se há iminência de um processo inflacionário, potencialmente explosiva porque a expectativa de elevação sistemática do nível de preços será incorporada nos juros.

$\mathrm{O}$ segundo caso parece ser mais interessante e remete mais diretamente à TFF. Quando as amortizações e os juros da dívida são pagos em moeda emitida exclusivamente para isso, espera-se, tudo o mais constante, que o nível de liquidez da economia aumente. Destarte os efeitos benéficos sobre o nível de investimento e produto que esse aumento causa, devemos estar atentos à configuração dos portfolios dos bancos. Estes terão crescentemente mais recursos não remuneráveis em suas carteiras. A procura pelos títulos remanescentes do governo aumentará e seu preço tenderá ao valor de face, eliminando, após isso, o mercado secundário. Como a cada período é esperada uma nova remessa de recursos que não geram renda em uma economia em que, também a cada período, há um aumento no patamar de preços, fica difícil entender por que os bancos irão se dispor a emprestar a taxas cada vez menores. Este caso configuraria, no seu limite, uma armadilha da liquidez com a característica sui generis de ameaça constante de um processo inflacionário. É por entender que variações nas quantidades de moeda com o público e os bancos são por demais delicadas que Bell (2000) expõe os pormenores do controle dos estoques de moeda e da determinação de uma taxa de juros de equilíbrio.

\section{CONSIDERAÇÕES FINAIS}

No presente trabalho procuramos mostrar alguns limites e possíveis extensões do artigo do professor Gerson Lima. Em particular, valendo-nos da mesma meto- 
dologia e a partir do relaxamento de algumas hipóteses restritivas através das quais Lima (2008) constrói seu modelo, procuramos demonstrar a possibilidade, com base na teoria econômica, da dívida pública não seguir, necessariamente, uma trajetória explosiva, ainda que todo o déficit público fosse financiado via emissão de novos títulos.

Em seguida, observando que a TFF possui baixa preocupação com a explicitação de uma teoria sobre a inflação, refutamos a conclusão do professor Gerson Lima sobre a compatibilidade de seu modelo com a proposta de regra de emissão monetária de Milton Friedman, também porque sua interpretação da teoria monetarista se mostrou equivocada, principalmente por ignorar o pressuposto desta de criação exógena da moeda. Por fim, buscamos demonstrar através do uso de contraexemplos que o equilíbrio não inflacionário de emissão de moeda obtido pelo autor configura apenas um caso particular, mesmo que aceitássemos sua hipótese subjacente de que o processo inflacionário somente pode ocorrer após o ponto de pleno emprego.

\section{REFERÊNCIAS BIBLIOGRÁFICAS}

BELL, S. A. (2000) “Do Taxes and Bonds Finance Government Spending?”. Journal of Economic Issues, 34(3): 603-620.

BELL, S. A. \& WRAY, L.R. (2003) "Fiscal Effects on Reserves and the Independence of the Fed". Journal of Post Keynesian Economics, 25(2): 263-271.

FOLEY, D. (2003) Unholy Trinity: Labor, Capital, and Land in the New Economy. London: Routledge.

FRIEDMAN, M. (1968) “The Role of Monetary Policy”. American Economic Review, 58(1): 1-17.

FRIEDMAN, M. (1969) The Optimum Quantity of Money and Other Essays. Chicago: Aldine Publishing Company.

FRIEDMAN, M. (1970) Milton Friedman's monetary framework. Chicago: The University of Chicago Press.

FRIEDMAN, M. (1977) "Nobel Lecture: Inflation and Unemployment". Journal of Political Economy, 85(3): 451-472.

GODLEY, W. \& LAVOIE, M. (2007) Monetary Economics: an Integrated Approach to Credit, Money, Income, Production and Wealth. Basingstoke: Palgrave Macmillan.

KEYNES, J. M. ([1936] 1973) The General Theory of Employment, Interest and Money, The Collected Writings of John Maynard Keynes, vol. VII. London: Macmillan.

LERNER, A. P. (1943) "Functional Finance and the Federal Debt". Social Research, 10: 38-51.

LIMA, G. (2008) "Matemática Agradável”. Revista de Economia Politica, 28(3): 471-489.

PATINKIN, D. (1965) Money, Interest, and Prices: an Integration of Monetary and Value Theory. New York: Harper \& Row.

WRAY, L. R. (1998) Understanding Modern Money: The Key to Full Employment and Price Stability. Cheltenham: Edward Elgar.

WRAY, L. R. (2002) “Seigniorage or Sovereignty?”. In: ROCHON, L. P. \& ROSSI, S. (2003), Modern Theories of Money. Cheltenham: Edward Elgar.

WRAY, L. R. (2003) “The Neo-Chartalist Approach to Money”. In: BELL, S. A. \& NELL, E. J. (2003) The State, the Market, and the Euro: Chartalism versus Metallism in the Theory of Money. Cheltenham: Edward Elgar. 